\title{
Healthy Living: Monitoring Blood Pressure at Home ${ }^{1}$
}

Karla P. Shelnutt ${ }^{2}$

Do you think that your blood pressure may be too high? Have you

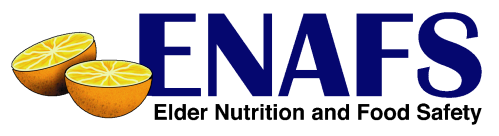
been diagnosed with high blood pressure (hypertension)? In either case it is important that you monitor your blood pressure at home as well as getting it checked at the doctor's office. This can help your doctor determine if you do have high blood pressure or if your treatment plan is working. Read on to learn how to monitor your blood pressure at home.

\section{How to Check}

The American Heart Association (AHA) recommends an approved automatic cuffstyle upper arm monitor to check your blood pressure. Follow these AHA guidelines to ensure an accurate reading:

1. Make sure the cuff fits.

2. Don't smoke, drink caffeinated beverages or exercise within 30 minutes of measuring blood pressure.

3. Sit with your back straight and supported.

4. Place your feet flat on the floor.

5. Support your arm on a flat surface like a table with your upper arm at heart level.

6. Wrap the cuff around your upper arm.

7. Take two or three readings one minute apart and record all results.

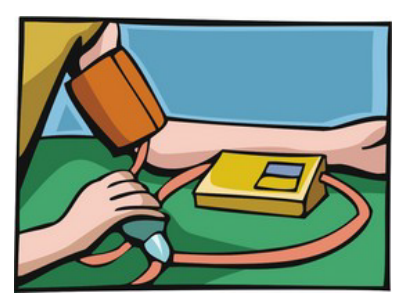

8. Take readings at the same time each day.

\section{What do the numbers mean?}

You may notice that your blood pressure varies throughout the day. This is normal and is why it is important to take your readings at the same time every day. The AHA has different categories for blood pressure to help you know what your numbers mean:

\begin{tabular}{|l|c|c|c|}
\hline Category & $\begin{array}{c}\text { Systolic } \\
\text { (mm hg) }\end{array}$ & & $\begin{array}{c}\text { Diastolic } \\
\text { (mm Hg) }\end{array}$ \\
\hline Normal & $<120$ & and & $<80$ \\
\hline Prehypertension & $120-139$ & or & $80-89$ \\
\hline & & & \\
\hline High & & & \\
\hline Stage 1 & $140-159$ & or & $90-99$ \\
\hline Stage 2 & $\geq 160$ & or & $\geq 100$ \\
\hline
\end{tabular}

Keep a log of your readings and take it to every doctor visit. This will allow your doctor to keep track of your blood pressure and change your treatment plan if needed. Use the log on the next page and make copies as necessary.

1. La versión en español de este documento es Vida Saludable: Monitoreando la presión arterial desde la casa (FCS8882-Span). This document is FCS8882, one in a series of the Department of Family, Youth and Community Sciences, Florida Cooperative Extension Service, IFAS, University of Florida, Gainesville, FL 32611. First published: November 2009. Please visit the EDIS Web site at http://edis.ifas.ufl.edu.

2. Karla P. Shelnutt, PhD, RD, assistant professor, Department of Family, Youth and Community Sciences, Florida Cooperative Extension Service, Institute of Food and Agricultural Sciences, University of Florida, Gainesville, FL 32611. 


\section{Blood Pressure Log}

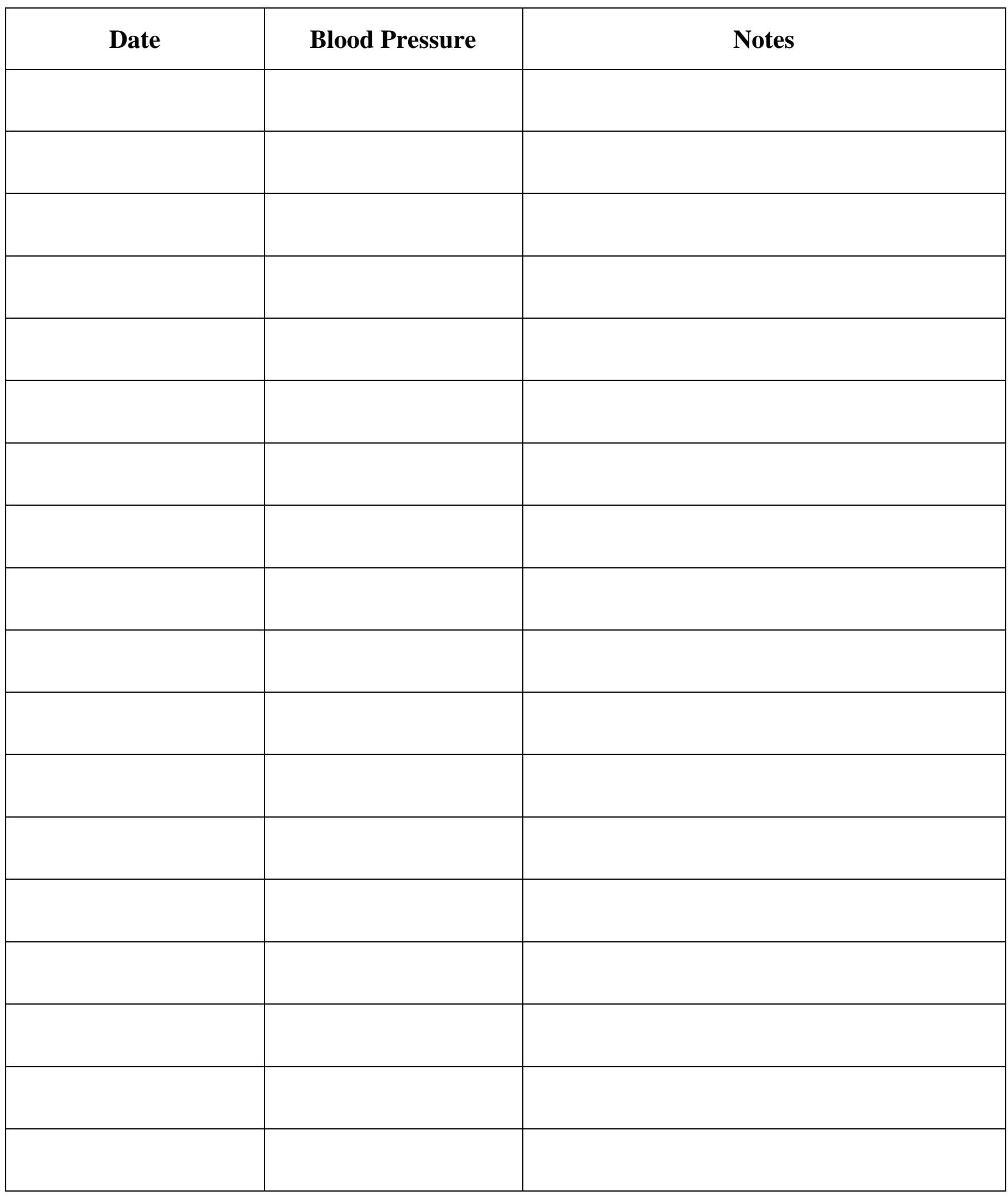

